\title{
1 Measuring, Modeling and Mapping Ecosystem Services in the Eastern Arc
}

2 Mountains of Tanzania

4 Authors

6 Brendan Fisher ${ }^{1,2^{*}}$, R. Kerry Turner ${ }^{1}$, Neil D. Burgess ${ }^{3}$, Ruth D. Swetnam ${ }^{4}$, Jonathan

7 Green $^{4}$, Rhys Green ${ }^{4}$, George Kajembe ${ }^{5}$, Kassim Kulindwa ${ }^{6}$, Simon L. Lewis ${ }^{7}$, Rob

8 Marchant $^{8}$, Andrew R. Marshall ${ }^{8}$, Seif Madoffe ${ }^{5}$, P. K. T. Munishi ${ }^{5}$, Sian Morse-Jones ${ }^{1}$,

9 Shadrack Mwakalila ${ }^{9}$ Jouni Paavola ${ }^{10}$, Robin Naidoo ${ }^{11}$, Taylor Ricketts ${ }^{11}$, Mathieu

10 Rouget $^{12}$, Simon Willcock ${ }^{7}$, Sue White ${ }^{13}$, Andrew Balmford ${ }^{4}$

12 1) Centre for Social and Economic Research on the Global Environment, University of 13 East Anglia, Norwich, NR4 7TJ, United Kingdom.

14 2) Program in Science, Technology and Environmental Policy, Woodrow Wilson School

15 of Public and International Affairs, Princeton University, Princeton, NJ 08544, USA:

16 bpfisher@Princeton.EDU

17 3) University of Copenhagen, Universitetsparken 15, DK-2100, Copenhagen, Denmark 18 and WWF-US, Conservation Science Programme, $125024^{\text {th }}$ Street, Washington DC, 19 USA.

20 4) Conservation Science Group, Department of Zoology, University of Cambridge, 21 Downing Street, Cambridge, CB2 3EJ, United Kingdom.

22 5) Faculty of Agriculture, Sokoine University of Agriculture, Chuo Kikuu, Morogoro, 23 Tanzania. 
1 6) Economic Research Bureau, University of Dar es Salaam, PO Box 35096, Dar es

2 Salaam, Tanzania.

3 7) School of Geography, University of Leeds, Leeds, LS2 9JT, UK.

4 8) Environment Department, University of York, Heslington, York, YO10 5DD, United

5 Kingdom.

6 9) Department of Geography, University of Dar es Salaam, PO Box 35049, Dar es

7 Salaam, Tanzania.

8 10) School of Earth and Environment, University of Leeds, Leeds, LS2 9JT, UK.

9 11) Conservation Science Programme, World Wildlife Fund $-125024^{\text {th }}$ St NW, 10 Washington DC, 20037, United States of America.

11 12) South African National Biodiversity Institute, Biodiversity Planning Unit, Private 12 Bag X101, Pertoria 0001, South Africa.

13 13) Integrated Environmental Systems Institute, University of Cranfield, MK43 OAL

$15 *$ Corresponding author

16

17

18

19

20

21 In light of the significance that ecosystem service research is likely to play in linking

22 conservation activities and human welfare, systematic approaches to measuring,

23 modeling and mapping ecosystem services (and their value to society) are sorely needed.

24 In this paper we outline one such approach, which we developed in order to understand 
1 the links between the functioning of the ecosystems of Tanzania's Eastern Arc Mountains

2 and their impact on human welfare at local, regional and global scales. The essence of

3 our approach is the creation of a series of maps created using field based or remotely

4 sourced data, data-driven models, and socio-economic scenarios coupled with rule-based

5 assumptions. Here we describe the construction of this spatial information and how it

6 can help to shed light on the complex relationships between ecological and social

7 systems. There are obvious difficulties in operationalising this approach, but by

8 highlighting those which we have encountered in our own case study work, we have also

9 been able to suggest some routes to overcoming these impediments.

\section{Keywords}

14 Ecosystem services, economic valuation, Eastern Arc Mountains, Tanzania, carbon 15 storage, biodiversity

\section{Introduction}

21 Current global concern regarding climate change, energy supply, food and water security

22 and the loss of biodiversity, has made it clear that a scientifically robust, policy-oriented

23 understanding of how these issues are interrelated will be essential for developing 
1 effective solutions (Holdren 2008). The concept of ecosystem services is one construct

2 for understanding how changes to our natural environment impact our welfare. How

3 climate change will affect agricultural yields and water availability, how biofuel-crop

4 expansion will affect biodiversity, and how growing human populations and economies

5 will affect forest cover, are all examples of the important questions that fall under the

6 rubric of ecosystem services research. In fact the use of the term 'ecosystem services' as

7 a research framework, has become much more prominent in the academic literature over

8 the past decade (Carpenter et al., 2006; Fisher et al., 2009), the publication of the

9 Millennium Ecosystem Assessment (MA, 2005), and the newly formed Intergovermental

10 science-policy Platform on Biodiversity and Ecosystem Services (IPBES - see

11 http://ipbes.net) has securely tied the importance of well-functioning ecosystems to

12 sustainable human welfare.

14 In light of the significance that ecosystem service research is likely to play in linking 15 conservation activities and human welfare, systematic approaches to measuring, 16 modeling and mapping ecosystem services (and their value to society) are urgently 17 needed (Carpenter et al., 2006). In this paper we outline one such approach, which we

18 developed in order understand the links between the functioning of the ecosystems of

19 Tanzania's Eastern Arc Mountains and their impact on human welfare at local, regional

20 and global scales. The essence of our approach is the creation of a series of maps created

21 using field based or remotely sourced data, data-driven models, and socio-economic

22 scenarios coupled with rule-based assumptions. Here we describe the construction of this

23 spatial information and how it can help to shed light on the complex relationships 
1 between ecological and social systems. We highlight some of the difficulties of

2 employing this approach, as well as some of the insights gained. While this project-

3 Valuing the Arc (VtA) - is still a work in progress, we are able to illustrate some of the

4 policy-ready outputs of such an approach.

6 Below we describe the biological and socioeconomic importance of the Eastern Arc

7 Mountains, the services they deliver, the sequence of steps in the mapping exercises, the

8 importance of scenario-building, and a brief example of how to apply such an ecosystem

9 services approach to linking conservation, human welfare and decision-making.

\section{Eastern Arc Mountains, Tanzania}

13 The Eastern Arc Mountains of Tanzania (EAM) comprise 13 mountain blocks stretching

14 the length of the country (Figure 1). The EAM is a globally important ecoregion

15 (Burgess et al., 2004; Burgess et al., 2006), and constitutes a large part of one of the

16 world's 34 hotspots of biological diversity (Mittermeier et al., 2004). It is home to

17 around 550 endemic plants and more than 90 endemic vertebrates (see Burgess et al.,

182007 for more in-depth information on biological importance of EAMs). In addition to

19 this unique biodiversity, these mountains also provide a range of ecosystem services and

20 related human benefits at local, regional and global scales - including timber and fuel

21 wood; water for irrigation, domestic use and hydroelectricity; carbon storage; medicinal

22 plants and other minor forest products; and nature-based tourism (Doggart and Burgess,

23 2005). 
4 At the same time this is an area of rapid land cover change, having lost $11 \%$ of its 5 primary forests and $41 \%$ of its woodlands since 1975 (FBD, 2006). This conversion is

6 driven by clearance for farmland, as well as increasing demand for timber and fuel wood.

7 These pressures, subsistence and commercial, are rational in the short term, especially in

8 a country where $44 \%$ of the population is food-insecure (UN, 2005) and over $90 \%$ of

9 household energy comes from burning biomass (Sheya and Mushi, 2000), but they seem

10 unlikely to provide a sustainable development strategy over the medium to long term.

11 The uniqueness of the Eastern Arc's natural assets, and their significance for human

12 welfare in Tanzania make this an important area for testing an ecosystem services

13 approach and investigating the potential 'win-wins' and tradeoffs between conservation

14 and human welfare.

15

\section{Measuring, Modeling, Mapping}

17

18 Figure 2 shows a conceptual layout for the approach we have developed for the EAM

19 project. It is shown as a series of mapped layers, but what is not shown is the underlying

20 data collection and modeling aspects of the approach. Here we unpack each of the layers

21 shown in figure 2 and discuss the data and modeling needs, some of the outcomes to date

22 and some of the difficulties we have encountered. 
[FIGURE 2 IN HERE]

\section{Inventory}

5 The first layer starts with an inventory. The ideal would be to gather all available

6 spatially-explicit data on the biophysical and social systems of interest. Data could

7 include landcover classes, information on climate and soils, demographic, infrastructural

8 and institutional variables, knowledge of resource use, etc. This information provides a

9 backdrop for the ecosystem services that might be of interest, but also is used in

10 developing the models that underpin other layers that characterize ecosystem services

11 (below). For example, knowledge of landcover, road layout and forest governance, might

12 shed light on the use of forest for providing timber and might also underpin a predictive

13 model of rates of extraction of non-timber forest products (NTFPs; Ahrends, 2005), and

14 timber-based products (Ahrends et al., 2010). In VtA, this initial stage included

15 workshops to update existing landcover maps, interviews of government, NGO and

16 academic stakeholders, and using past research to identify the focal ecosystem services

17 for the project. From stakeholder engagement and expert opinion gathered across three

18 continents we determined that Valuing the Arc (VtA), given the resources available,

19 should focus on five categories of services and benefits - carbon, water, timber and

20 NTFPs, pollination and biodiversity. Each category contains a suite of services and

21 benefits for which spatially explicit data was sought for the inventory layer (Table 1).

[TABLE 1 IN HERE] 
2 Wherever possible these datasets were mapped to explore spatial interactions between

3 datasets, highlight the social context of the biophysical data and identify places where

4 further primary data collection is necessary or where modeling needs to fill in

5 information gaps. For example, from the Tanzania Socio-Economic Database we were

6 able to get population statistics at a coarse district level. From the Center for

7 International Earth Science Information Network (CIESIN, 2005) we could get a

8 modeled surface of the population of Tanzania on a 2.5 arc-minute grid. However, this

9 layer showed people living within Nature Reserves, which we know from direct

10 observations to be incorrect. Here, our inventory process identified a crucial layer of

11 spatial information that needed improvement.

13 This step also helped to identify three focal river basins for fine-grained analysis and

14 fieldwork: the Sigi Basin (draining the Usambara Mountains), the Ruvu Basin (draining

15 the Uluguru Mountains) and the Kilombero Basin (draining the Udzungwa Mountains).

16 The three basins were chosen because they are relatively well documented, have

17 important ecosystem service flows to local and downstream users, and are the subject for

18 ongoing policy processes. For example, the River Ruvu which drains the Uluguru

19 mountains supplies the capital Dar es Salaam with a large proportion of its fresh water.

20 Since the 1950s there has been a steady and significant decline in the baseflow of the

21 river which is causing serious concerns for the maintenance of supply to the city (Doggart

22 and Burgess, 2005). This decline has been linked to degradation in the forested areas of

23 the catchment (FBD, 2006). In addition to these biophysical characteristics the Ruvu has 
1 a range of governance structures in place with varying ownership and management

2 combinations including some forests co-managed by local people through Participatory

3 Forest Management agreements (Blomley et al., 2008). While much of the data collected

4 at this stage focused on the entire EAM study region, more detailed datasets were

5 collected for these three study basins in order to create realistic maps and robust models,

6 which will eventually be used to parameterize models for the whole of the EAM.

7

8 The issue of water supply to downstream users from a forested area that has few

9 resources available for its management, is also now being addressed through Payment for

10 Environmental Services schemes (Fisher et al., 2010), which are delivering money from

11 the city of Dar es Salaam to forest adjacent communities to improve their land

12 management with respect to water regulation.

\section{Service Production}

16 The next layer involves understanding how, where and at what rate ecosystem services

17 are produced on the landscape. This requires a biophysical understanding of ecosystem

18 processes from theory through to measurement and modeling. At the most basic level,

19 land cover maps can provide surface information about the types of services a landscape

20 may provide (e.g. carbon sequestration, water supply, climate regulation). Process

21 models and ground measurements can help to further identify, scale and quantify

22 services. 
1 As an example, in the EAM we have been measuring carbon storage at different

2 elevations and within the vegetation of different land cover types, to develop a service

3 production map of carbon storage. In addition a sub-set of plots has been monitored for 3

4 years to assess rates of carbon sequestration. One of the difficulties here is the fact that

5 we often measure phenomena where they are most obvious - in this case, measuring

6 carbon in forests containing many large trees. At the inventory phase we realized that the

7 majority of previous research quantifying the carbon density of vegetation in the EAM

8 has taken place in the high carbon storage montane forests, with little work done in

9 woodlands, degraded forests, crop mosaics or pure cropland. There is an equally difficult

10 problem to overcome when building hydrological models of service production. Our

11 early efforts to produce a map of "water production" suggested the relatively dry Selous

12 area was important for water production. This error arose because a globally available

13 rainfall surface was extrapolating rainfall across widely spaced meteorological and river

14 gauges, with one gauge in a high rainfall area close to the mountains, and the next in the

15 dry centre of the Selous. The reality, not captured by the models, was a much steeper

16 rainfall decline within a few kilometers of the mountain. Here the task of generating a

17 first-cut map led to a series of insights about our modeling process and identified the

18 need for further data collection. While production maps are unique to individual services

19 a simple overlay will indicate areas on the landscape where a bundle of services may be

20 produced.

\section{Service Flow}


1 Next, the service production maps are combined with an understanding of how services

2 spread through the landscape and information on land use and topography to estimate

3 where services flow from their point of production. There are a variety of spatial

4 relationships between where ecosystem services are produced and where the benefits of

5 those services are enjoyed, and therefore individual flow maps could be needed for each

6 service. Some services flow globally, others may only be experienced at their point of

7 production, and some are constrained to flow in a particular direction (Figure 3). For

8 example, a forest can only provide water regulation services to areas that are downstream

9 of them. Mapping such flows requires the integration of biological processes (e.g. water

10 uptake by plants) and physical processes (e.g., hydrological networks). One of the

11 difficulties in this stage is that obtaining a fine-scale understanding of flows can require

12 prohibitive amounts of data. For example, our timber production layer tells us where

13 such a benefit is produced, and from extensive transect and disturbance data (see Table 1)

14 we know how much 'flows' from our forests, but mapping exactly where the good

15 'flows' across the landscape requires extensive fieldwork and market surveys. From pilot

16 surveys and published NGO reports, we are building a heuristic decision model to

17 allocate these timber flows based on the typical uses of individual species and their unit

18 cost. For example, species with a higher end use value are likely to travel further and to

19 wealthier markets (e.g. larger cities). Since an ecosystem service is inherently an

20 anthropocentric concept understanding these flows without linking them to actual

21 beneficiaries only gives an example of 'potential' flows of services. Real flows

22 materialize when beneficiaries are present. 
[FIGURE 3 IN HERE]

\section{Beneficiaries}

4

5 In order to move from potential flows to realized flows of benefits we next need to have

6 an understanding of where people are on the landscape and whether they utilize these

7 flows. The concept of ecosystem services is human-focused and therefore only exists if

8 there are human beneficiaries. If there are no human benefits (at any scale) then we are

9 not talking about ecosystem services, but rather ecosystem processes or functioning.

10 Therefore, connecting the flow of services to people who may consume them, i.e.

11 translating potential service flows into benefits, is a necessary step.

13 Beneficiary layers are obtained from maps of service flows, land use, combined with data

14 on the spatial distribution of people on the landscape and their use of land and resources.

15 For example, in the average year $60 \%$ of all electricity produced in Tanzania comes from

16 hydroelectric power from dammed EAM rivers (The Economic Survey, 2008). The

17 beneficiaries for this (10\% of the Tanzanian population) are located in the major cities,

18 especially Dar es Salaam, but the production areas, and those areas important for making

19 sure the rivers flow throughout the year are likely to be well upstream from the electrified

20 urban areas. Additionally, about half of the electricity produced (in 2007) was used for

21 commercial and industrial ends (The Economic Survey, 2008), offering a different suite

22 of benefits compared to household electricity usage. 
1 Again difficulties lie in accurately placing people on the landscape and accurately

2 assessing their use of the service (and where necessary the timing of that use). For

3 example, knowing how small-scale irrigators benefit from water regulation services

4 requires fine-grained and expensive data collection across a wide range of social and

5 ecological contexts, and mapping how households use water for domestic uses requires

6 extensive household surveys. Once this data is obtained, both the service flow and the

7 beneficiaries become mappable elements.

9 Together the first four layers provide information about the flow of ecosystem services 10 across a landscape to beneficiaries. In some cases translating service flows to

11 beneficiaries will have to be an iterative process, since service provision can change

12 across the landscape as a result of direct use. For example, removal of freshwater for

13 irrigation in the upper Uluguru watershed of Tanzania will change the level of

14 downstream service flow, leaving less for the downstream beneficiaries in Dar es Salaam,

15 and therefore changing the service flow map via quantity available at different potential

16 use points. A related key issue here is gaining an understanding of where services are

17 mutually supportive and where there are tradeoffs amongst services. For example,

18 charcoal and timber production may negatively affect water regulation in the basins,

19 where as carbon storage may be positively correlated with water regulation services in a

20 given catchment. It is likely that the models used to integrate across services will be

21 pared-down versions of the individual service models.

22

\section{Benefits}


2 After understanding where services are produced, how they flow and who benefits from

3 their flow, the next layer needed is one that gives a magnitude to the importance of that

4 benefit. This is what we consider a value layer. Probably the most common metric of

5 value for ecosystem service research is monetary, but alternative evaluation layers may

6 be constructed incorporating for example, indices of human vulnerability. For many

7 services, the value of a given level of service provision will change across the landscape

8 because of geographical variation in either biophysical supply or human demand. For

9 instance, the value of clean water provision will be affected by how wealthy the

10 beneficiaries are; what they use it for; and how scarce or abundant water is across a

11 landscape. In the EAM our dataset for charcoal prices covering 63 locations shows that

12 prices in Dar are up to twice as high as in other urban areas, and this is not simply a

13 reflection of transportation costs (see Edge et al., 2009). Here price is only a proxy for

14 value, but the data does show spatial variation in value. For other services the financial

15 value will be constant across landscapes or even globally, as in a uniform global value for

16 carbon storage (Strassburg et al., 2009). The latter does not suggest that the value of

17 climate regulation is homogeneous across the landscape, just the market price as its value

18 proxy per tonne of carbon stored.

20 A benefit from using monetary valuation across services is that it allows for

21 commensurability in deriving "net" benefits and costs, by bringing each service assessed

22 into a common metric. In Tanzania we are deriving our value layer through multiple

23 methods. For example, we will evaluate the benefits of water provision for irrigation by 
1 a production function approach - i.e. assessing the additional productivity and value

2 added to net crop receipts by irrigation water. The values for timber, NTFPs and

3 hydroelectric power services will also be imputed using market prices in a production

4 function approach. Market and household surveys can be a direct way to get at these

5 values, but one thing we have learned from our fieldwork was that our expectations of

6 modeling several similar goods across such a large area were optimistic. For example,

7 we are able to create a list of a few dozen distinct NTFPs. However, many of these are

8 only collected in certain contexts, at certain locales, or under certain conditions (e.g.

9 rainy season). In response to our findings from the market and household surveys we are

10 therefore modeling only the most commonly collected NTFPs - poles, firewood,

11 mushrooms, charcoal, thatch as well as trying to bundle some wild fruits and vegetables.

12 These are products whose production we can attempt to model and to which we can also

13 attribute values, as well as examine potential substitutes in the market place. Therefore

14 we exclude medicinal herbs, honey, fibers for baskets, rope and fodder collection from

15 our modeling.

17 The benefits of biodiversity conservation also present a complex valuation problem, 18 including accounting for the differences between 'local' people and their value 19 preferences and residents in international 'donor' countries (Horton et al., 2003; Hanley 20 et al., 2003). In VtA our objective was to estimate the willingness to pay of UK (donor 21 country) residents for conserving wildlife in the EAM, using a split sample survey design

22 (Morse-Jones et al., 2010). A choice experiment method was used to present respondents

23 with a series of questions describing the possible outcome for wildlife if current 
1 development pressure trends continue and if conservation measures are implemented. In

2 the choice experiment, respondents were asked to choose their most preferred option in

3 each question. The options were described in terms of three attributes (1) the number of

4 unique species saved; (2) the number of non-unique species saved and (3) the donation by

5 the household to enable outcomes to be achieved. The levels for the donation were based

6 on a literature review and pre-testing. By varying the attribute levels across the options

7 and modeling how this affects choices we were able to estimate willingness to pay for

8 total changes in wildlife conservation, as well as for changes in the individual attributes.

9 The experiment suggested that UK residents were willing to pay on average $£ 53$ (2008

10 GBP) per household per annum for conservation efforts in the EAM (Morse-Jones et al., $112010)$.

\section{Costs}

15 Benefit values are only one side of the coin. In order to make robust policy

16 recommendations we need to have an understanding of both the benefits of a functioning

17 ecological landscape as well as the costs of providing that landscape. The costs of 18 conserving landscapes for ecosystem service provision include not just the direct 19 management costs of interventions (such as salaries for park guards) but also the 20 opportunity costs for local stakeholders (i.e. their net benefits foregone as a result of 21 conservation), implementation and transaction costs of a conservation intervention, 22 possible acquisition costs, and any damage costs that might be incurred (Naidoo et al., 23 2006) - in our case crop damage would most likely be caused by vervet monkeys, 
1 baboons and bushpigs. In the EAM, the opportunity costs of conservation are found by

2 examining the profitability of the foregone farming and fuel collection opportunities. For

3 example, in some districts of the EAM up to $95 \%$ of the people are either employed in

4 agriculture or are subsistence farmers, meaning that any further designation of restricted

5 land use could directly affect opportunities for agricultural expansion. We have found

6 that, on the district scale, the agricultural opportunity costs of conservation vary widely

7 (NPV $\$ 400 /$ ha- $\$ 8000 /$ ha), and that by including the profit foregone from charcoal

8 production (in the case of a woodland being converted first for charcoal and then

9 agricultural use) the opportunity cost can increase by $12-167 \%$ (b.fisher unpublished

10 data). An extensive field survey showed that variation in yield between farmers and

11 across years makes it difficult to model opportunity costs at a fine scale using data from

12 household surveys, which means these costs will likely be modeled at a coarser scale

13 such as the ward level (i.e. several villages).

14

15 Another difficulty we have faced with modeling costs is the availability of data regarding

16 the management and implementation costs of conservation. In some contexts this type of

17 information might be readily available, but in our EAM project it requires a concerted

18 effort to collate data from online records, government reports in scattered locations, and

19 interviews with government staff. The range of different governance types which are

20 used to manage the landscape also make it difficult as understanding the costs needed to

21 manage a central government administered Nature Reserve will require different data-

22 acquisition strategies than, say, those bearing on the management of a village-based

23 forest reserve. 
2 Both the valuation and cost steps require interaction with the development of scenarios

3 (see below) in order to construct some form of 'marginal' values. For example, the

4 marginal benefits of any given ecosystem service and the costs for securing the delivery

5 of that service are functions of the difference between two states of the world - perhaps

6 the current state and one where conservation schemes are initiated. The development of

7 scenarios and their integration with the modeling and mapping exercises is explained in

8 more detail below.

10 Mapping Winners and Losers

12 The advantage of measuring costs and benefits in the same monetary units is that you can

13 combine the benefits value layer and the cost layer into one map. The result is a map

14 with clearly demarcated areas of net gains and net losses. For example, if a current forest

15 reserve involves high locally-incurred costs (e,g,. opportunity or damage costs etc.) and

16 limited local benefits (e.g. through NTFP provision), but delivers significant benefits

17 (such as water flow regulation) at low cost (e.g. limited management cost) to people

18 living in Dar es Salaam, then the map may show net losses nearby and net gains further

19 away. An aggregated non-spatial summary of total costs compared to total benefits would

20 not reveal this spatial variation, and would therefore not indicate where cost-benefit

21 differentials are the smallest. Yet understanding such asymmetries is evidently crucial

22 for the design of equitable policy interventions. In the EAM, CARE and the World

23 Wildlife Fund are facilitating project work on the Ruvu River that aims to link the 
1 beneficiaries of the water flowing from the Uluguru Mountains (mainly in Dar es

2 Salaam) to those living and managing the land in these mountains. The intention is to

3 ensure that land-use practices in the mountains help maintain water quality and that major

4 water users pay the communities for their efforts and for foregone opportunities of forest

5 conversion (Fisher et al., 2010). Providing maps of where these benefits are being

6 produced and the relative costs of producing them will aid in targeting specific sub-

7 basins, but also indicate the magnitude of compensation required.

$9 \quad$ Scenario Building

11 The above steps all involve modeling phenomena that are dynamic and will change under

12 different possible futures. Exploring the possible consequences of such change is vital if

13 an understanding of ecosystem services is to be useful to decision-makers. They need to

14 know not just about the gross values of services delivered from a particular area but about

15 the likely net differences in value (incorporating costs as well as benefits) arising from

16 the decision confronting them (say, to sanction a forest to be converted or not).

17 Understanding these values spatially can help to understand how to optimize a landscape

18 for a given goal (e.g. net benefit return), aid in comparing alternative policy impacts, or

19 highlight potential future changes driven by different potential futures.

21 Key drivers of resulting differences in service values include land use change,

22 demographic shifts, changes in patterns of demand, technological innovations and climate

23 change. To explore the impact of such changes on human welfare requires scenario 
1 building. Typically, scenarios are presented as 'storylines' which are internally

2 consistent and offer plausible future possibilities (Gallopin et al., 1997; Peterson et al.,

3 2003; Raskin, 2005; MA, 2005). Rather than representing a specific prediction each

4 scenario should be thought of as a description of a possible future which has plausibility

5 given the knowledge and assumptions on which it is based. When done thoroughly

6 scenarios can guide policies towards specific end goals such as increasing human welfare

7 or equity (Turner, 2005). Scenario building has become an important part of multi-

8 disciplinary research being widely used in land use planning (Xiang and Clarke, 2003;

9 Verburg et al., 2006), climate change analysis (IPCC, 2007) and conservation planning

10 (Osvaldo et al., 2000) and, increasingly, in ecosystem service assessments (Castella et al.,

11 2005; MA, 2005; Walz et al., 2007).

13 In relation to our mapping approach, future scenarios would change each of the layers in

14 figure 2. For example, a future with an increase in road infrastructure would alter the

15 base inventory layer (and any layers that in turn informed by it); whilst a future with

16 more forest conservation would affect the production, flow, beneficiaries, benefits and

17 costs layers, and therefore the resultant map of winners and losers.

19 For VtA, we developed two socio-economic scenarios with Tanzanian stakeholders in a 20 series of participatory workshops (see Swetnam et al. 2010). Both scenarios relate to the 21 year 2025 (Table 2). Matazamio Mazuri (MM) means 'hopeful expectations' in 22 Kiswahili and represents a future where Tanzania fully meets its stated policy goals on 23 poverty alleviation and natural resource management, but still reflects the reality of a 
1 population growth and economic pressures. Kama Kawaida (KK) means 'as usual' in

2 Kiswahili and corresponds to a business-as-usual scenario where a growing population

3 combined with ongoing resource exploitation leads to continued environmental

4 degradation and steady-to-declining family income.

[TABLE 2 IN HERE]

8 Our scenario-building process continued with more formal descriptions of how the

9 storylines impact on different sectors (agriculture, water supply, tourism, forestry and 10 population). The sectoral impacts were then translated down to ordinal-level impacts on

11 specific human-environment interactions (e.g. "large increase in area under agriculture").

12 Finally, further discussion established a series of rules for translating these ordinal scores 13 into changes in our mapped surfaces (Swetnam et al., 2010). So in the case of a large

14 expansion in agriculture we needed a rule for establishing the location and magnitude of 15 this expansion, and so considered that agriculture expands in areas abutting existing 16 agricultural land until the threshold prescribed in the storyline is met (e.g 10\% increase in 17 agriculture). Once such mapped outputs have been generated they can then be used as 18 revised inputs to the layers in figure 2, thereby generating descriptions of the plausible 19 gains and losses that may be incurred by specific future courses of action.

\section{Illustrative Example of the Mapping Approach}


2 Here we provide a brief stylized example of how the mapping approach can help provide

3 insights for policy and management decisions based on some preliminary results from our

4 project. We focus on the carbon stored in two Forest Reserves, Shagayu and Image (both

$5 \sim 80 \mathrm{~km}^{2}$ in size), and examine the relative costs and benefits of the conversion of these

6 forests by expanding subsistence agriculture.

[FIGURE 4 IN HERE]

10 Starting with the inventory layer, we map population around the reserve, the reserve

11 boundaries, and land cover within and surrounding the reserves (Figure 4). The

12 production layer considered here is simply the carbon stored in each landscape as in this

13 example we are only concerned with a single ecosystem service (Shagayu: mean 325

$14 \mathrm{tC} / \mathrm{ha}$; Image: mean $277 \mathrm{tC} / \mathrm{ha}$ ). Likewise, for this initial test we generate our production

15 layer simply using mean values from the literature of carbon storage in each land-use

16 type, for each of four pools: above ground, below ground, soil and dead matter. The flow

17 and beneficiary layers are unmapped as the benefits of carbon storage, i.e. climate

18 regulation from this carbon not entering the atmosphere, are assumed to accrue globally

19 regardless of where the carbon is stored (because $\mathrm{CO}_{2}$ is a well-mixed gas in the

20 atmosphere). The value layer could be derived using a range of existing monetary values

21 for carbon: voluntary carbon markets $\left(\sim 5 / \mathrm{tCO} \mathrm{CO}_{2 \mathrm{eq}}\right)$, compliance markets such as the

22 European Trading Scheme $\left(\sim \$ 18 / \mathrm{tCO}_{2 \mathrm{eq}}\right)$, and damage cost avoided estimates $(\sim \$ 15-$

$\left.23 \$ 50 / \mathrm{tCO}_{2 \mathrm{eq}}\right)(\mathrm{Tol}, 2005)$ that are all readily available and defensible under differing 
1 assumptions. For our example, however, we will forego appending a value to the carbon

2 and discuss the important underling issues further below.

3

4 For the cost layer we created an opportunity cost based on the net rents from the top five

5 crops grown in the Lushoto and Kilolo districts where the reserves occur (Shagayu and

6 Image, respectively) based on the average crop yield and regional market price (NPVs 30

7 years $r=10 \%$ ). We also added the foregone benefits of charcoal production specific to

8 the forests in these districts that are converted under our scenario. These costs are just an

9 approximation of the opportunity costs at these forest reserves, because for one, they are

10 based on district values. We also added management and implementation costs for

11 managing a carbon-offset project for the projected converted areas (proxy for managing

12 the forest reserves) (Borner and Wunder 2008). Specifically, the opportunity cost was

13 calculated as:

14

$15 \quad O_{x}=\sum_{i}^{I}\left(y_{i x} a_{i x} p_{i}\right)-C+.34 G n+M$

16

17 Where $O_{x}$ is the opportunity cost of conservation in $x . a_{i x}$ is the area planted with crop $i$ in

$18 x(h a), y_{i x}$ is the yield of crop $i$ in $x$ in tonnes/ha (Tanzanian Agricultural Census 2003); $P_{i}$

19 is the price of crop $i$ from regional price data in USD/tonne (FAO's PriceStat database),

20 and $C$ is the cost of inputs including cost of seeds, transportation, land, labour and

21 fertilizer (b. fisher unpublished data; Tanzanian Agricultural Census 2003). 
$1 G$ is the aboveground biomass in a given hectare (in $\mathrm{kg}$ ), and .34 represents a conversion

2 of biomass to charcoal based on kiln efficiencies and published field work and $n$ is the

3 profit from charcoal production ( $\$ / \mathrm{kg}$ ) (Malimbwi et al., 2007; Van Beukering et al.,

4 2007). $M$ is the proxy measure for management and implementation costs (Borner and

5 Wunder, 2008).

6

7 When we add up the costs of conserving the forest reserves (countering the conversion

8 scenario) we get values of $\$ 10.6$ million (\$2200/ha) and $\$ 5.6$ million $(\$ 1660 / \mathrm{ha})$ for the

9 Shagayu and Image reserves respectively. In the conversion scenario, from our modeling,

10 we know that the Shagayu and Image Forest Reserves lose 1.4 and .9 million tonnes of

11 carbon respectively. Here rather than applying a value to each tonne of carbon we can

12 simply calculate the necessary price of carbon in order to offset the opportunity and

13 management costs of maintaining the two forest reserves, based on this stylized example.

14 The breakeven carbon price for the Shagayu Reserve is $\$ 2.06 / \mathrm{tCO}_{2}$, meaning that a

15 carbon price set at that level could compensate the costs incurred in continuing to

16 conserve that landscape. Similarly, the breakeven carbon price for the Image Forest

17 Reserve is $\$ 1.70 / \mathrm{tCO}_{2}$ (see table 3). The knock-on policy question is whether these

18 carbon payments can be realized.

20 This example looks at just one benefit (carbon storage), two costs (opportunity and 21 management costs) and one scenario. A more comprehensive assessment of the 22 conversion costs and benefits of theses two forest reserves would incorporate a fuller 23 suite of ecosystem services including water regulation, pollination, and other NTFPs. 
1 Additional costs not accounted for here include soil depletion, damage costs, and some

2 measurement relating to how conversion or conservation might affect market prices of

3 agricultural and timber products. However, even this simple example illustrates our

4 approach, and provides insight on the partial costs and benefits of conservation $\mathrm{v}$.

5 conversion. The example also points out the spatial aspect of production, costs and

6 benefits as they differ greatly between the forest reserves. Further, these reserves were

7 selected because they are similar in size, but set in contrasting locations. The Shagayu

8 occurs in the heavily populated Usambara Mountains, while the Image is located in the

9 sparsely populated Udzungwa Mountains. This distinction is critical if we were not

10 concerned simply with the value of carbon, but rather with how many people would be

11 impacted by foreclosing their option to convert forest into agriculture. In this case the

12 stakeholders who benefit from carbon storage are largely global, while those paying the

13 greatest share of the costs are local. Table 3 shows that there are an estimated 35793

14 people living within $5 \mathrm{~km}$ of the Shagayu Reserve, but less than 700 people within $5 \mathrm{~km}$

15 of the Image Reserve. If the Tanzania Government, or a carbon buying institution, had to

16 decide which forest to conserve they could be faced with a choice of foreclosing the

17 opportunities of some percentage of 35 thousand people or some percentage of the 700

18 people. The latter might be more plausible politically and potentially more easily

19 compensated. Alternatively, they could see these population disparities as pressures and

20 an argument that by protecting the Shagayu they are demonstrating additional carbon

21 saved in the face of a greater conversion threat.

[TABLE 3 IN HERE] 
2 The simple example of our approach allows us to consider multiple policy or 3 management options in the face of a changing landscape, but in the future will enable

4 such decision-making on an analysis of several services, multiple costs and a suite of

5 scenarios, delivering an added depth of information to the decision-making process.

9 Conclusion

11 In the past few years we have learned much about how ecosystem service research can

12 best inform decision-making. Key lessons include the importance of integrating cost 13 data, in addition to benefit data (Ando et al., 1998; Naidoo et al., 2006); making spatially-

14 explicit assessments at both ecologically and policy-relevant scales (Chan et al., 2006;

15 Rouget et al., 2006); and employing contrasting scenarios that are meaningful to

16 decision-makers (Balmford et al., 2008). Our approach described here incorporates these

17 insights and delivers policy-relevant information in an easily accessible way. There are

18 obvious difficulties in undertaking this approach, but by highlighting those which we

19 have encountered in our own case study work, we have also been able to suggest some

20 routes to overcoming these impediments.

22 Our approach was designed to address the impacts of different policy options on

23 ecosystem services and their role in providing human well-being. It is intimately 
1 concerned with equity issues, in that a key output is a map of the relative winners and

2 losers of various different future scenarios and policies. We also see it as a general

3 approach, which can be applied at various scales and with varied levels of input detail.

4 Of course there remain several key challenges within our project and the larger

5 ecosystem service research agenda like: How do we incorporate the importance to

6 human welfare of those services which conventional economic valuation fails to

7 meaningfully express? What are the transaction costs of applying such a research

8 program? How can such an approach be undertaken in contexts where data and funding

9 are limited and institutions weak? How do we understand service flows and values that

10 change spatially and temporally over short time scales, e.g. seasonal variations,

11 migrations, fluctuating stocks? How can we incorporate ecosystem services and their

12 valuation into climate change models that include representations of the land surface

13 (Doherty et al., 2010)? This set of questions represents only a fraction of those that

14 remain for more robust ecosystem service analysis. While these challenges may seem

15 significant, the importance of delivering accurate and timely information on the role well-

16 functioning ecosystems play in human welfare will continue to grow.

19 Acknowledgements

20

21 Valuing the Arc (www.valuingthearc.org) is a large collaborative programme funded by

22 the UK Leverhulme Trust, with additional support from the UK Royal Society (SLL) and

23 the Packard Foundation in the USA. 


\section{References}

Ando, A., J. Camm, et al. 1998: Species distributions, land values, and efficient conservation. Science 279(5359), 2126-2128.

Ahrends, A. 2005: Patterns of degradation in lowland forests in coast regions, Tanzania. Unpublished MSc thesis, University of Greifswald, Germany.

Ahrends, A., N. D. Burgess, et al. (2010). "Predictable waves of sequential forest degradation and biodiversity loss spreading from an African city." Proceedings of the National Academy of Sciences of the United States of America 107(33): $14556-14561$.

Balmford, A. P. 2008: The Economics of Biodiversity and Ecosystems: Scoping the Science. European Commission.

Blomley, T., K. Pfliegner, J. Isango, E. Zahabu, A. Ahrends, and N. Burgess. 2008: Seeing the wood for the trees: an assessment of the impact of participatory forest management on forest condition in Tanzania. Oryx 42,380-391.

Borner, J. \& Wunder, S. 2008: Paying for avoided deforestation in the Brazilian Amazon: from cost assessment to scheme design. International Forestry Review 10, 496511.

Burgess, N. D., J. D'Amico Hales, E. Underwood, E. Dinerstein, D. Olson, I. Itoua, J. Schipper, T. Ricketts, and K. Newman. 2004: Terrestrial ecoregions of Africa and Madagascar: a continental assessment. Island Press, Washington DC.

Burgess, N. D., J. D’Amico Hales, T. Ricketts, and E. Dinerstein. 2006: Factoring species, non-species values and threats into biodiversity priority-setting across the ecoregions of Africa and its islands. Biological Conservation 127,383-401. 
Burgess, N. D., Butynski, T. M., Cordeiro, N. J., Doggart, N. H., Fjeldså, J., Howell, K. M., Kilahama, F. B., Loader, S. P., Lovett, J. C., Mbilinyi, B., Menegon, M., Moyer, D. C., Nashanda, E., Perkin, A., Rovero, F., Stanley, W. T., Stuart, S. N., 2007: The biological importance of the Eastern Arc Mountains of Tanzania and Kenya. Biological Conservation 134, 209-231.

Burgess, N.D., Clairs, T., Danielsen, F., Dalsgaard, S., Funder, M., Hagelberg, N., Harrison, P., Haule, C., Kilahama, F., Kilawe, E., Lewis, S., Lovett, J.C., Lyatuu, G., Marshall, A., Meshack, C., Miles, L., Munishi, P., Nashanda, E., Shirima, D., Swetnam, R., Willcock, S., Williams, A., Zahabu, E 2010: Getting ready for REDD+ in Tanzania: a case study of progress and challenges. Oryx

Carpenter, S. R., R. DeFries, T. Dietz, H. A. Mooney, S. Polasky, W. V. Reid, and R. J. Scholes. 2006: Millennium Ecosystem Assessment: Research needs. Science $314,257-258$.

Castella, J. C., Ngoc Trung, T., Boissau, S., 2005: Participatory Simulation of Land-Use Changes in the Northern Mountains of Vietnam: the Combined Use of an AgentBased Model, a Role-Playing Game, and a Geographical Information System. Ecology and Society 10(1), 27. http://www.ecologyandsociety.org/vol10/iss1/art27/.

Chan, K. M. A., M. R. Shaw, et al. 2006: Conservation planning for ecosystem services. Plos Biology 4, 2138-2152.

CIESIN (2005). Gridded Population of the World, Version 3 (GPWv3). Center for International Earth Science Information Network (CIESIN), Columbia University; 
Centro Internacional de Agricultura Tropical (CIAT). Palisades, NY. http://sedac.ciesin.columbia.edu/gpw/

Doggart, N.D. and Burgess, N.D. (eds). 2005: State of the Arc in 2005: special issue on Eastern Arc Mountains monitoring baselines. The Arc Journal 19, 1-32.

Doherty, R. M., S. Sitch, et al. (2010). "A green future for East Africa: implications of future climate and atmospheric $\mathrm{CO} 2$ content on regional carbon cycling and biogeography " Global Change Biology 16: 617-640.

8 The Economic Survey 2007 (2008) The Ministry of Finance and Economic Affairs, Dar es Salaam, Tanzania.

10 Edge, A, N.D. Burgess, and R. Malimbwi (2009) The charcoal trade in eastern Tanzania, Miombo, 4: 5-8.

12 Fisher, B., Turner, R. K., Morling, P., 2009: Defining and classifying ecosystem services for decision making. Ecological Economics 68, 643-653

14 Fisher, B, Kulindwa, K., Mwanyoka, I., Turner, R.K. and Burgess, N.D. 2010: Common pool resource management and PES: Lessons and constraints for water PES in Tanzania. Ecological Economics 69, 1253-1261.

17 Forestry and Beekeeping Division 2006: Forest Area Baseline for the Eastern Arc Mountains. Compiled by Mbilinyi, B.P., R.E. Malimbwi, D.T.K. Shemwetta, Songorwa, E. Zahabu, J.Z. Katani and J. Kashaigili for Conservation and Management of the Eastern Arc Mountain Forests, Forestry and Beekeeping

21 Division, Ministry of Natural Resources and Tourism, Dar es Salaam. www.easternarc.or.tz 
1 Gallopin, G., Hammond, A., Raskin, R. D., Swart, R. J., 1997: Branch points: global scenarios and human choice. Stockholm Environment Institute, Stockholm, Sweden.

4 Hanley, N., Macmillan D, Patterson I, and Wright, R.E. 2003 : Economics and the design of nature conservation policy: a case study of wild goose conservation in Scotland using choce experiments. Animal Conservation: 6, 123-129

Holdren, J. P. 2008: Science and Technology for Sustainable Well-Being. Science 319, 424-434.

9 Horton, B., Colarulla, G., Bateman, I. J., and Peres, C.A. 2003: Evaluating non-user willingness tp pay for a large scale conservation programme in Amazonia: a UK/Italian contingent valuation study. Environmental Conservation 30, 139-146

R. E. Malimbwi, E. Zahabu, B. Mchome (2007) Situation analysis of Dar es Salaam

IPCC, 2007. Climate Change 2007: Synthesis Report. Contribution of Working Groups Charcoal Sector. World Wildlife Fund.

18 Millennium Ecosystem Assessment. 2005: Island Press, Washington, DC.

19 Mittermeier, R. A., P. Robles-Gil, M. Hoffmann, J. D. Pilgrim, T. M. Brooks, C. G. Mittermeier, J. L. Lamoreux, and G. Fonseca. 2004: Hotspots Revisited: Earth's Biologically Richest and Most Endangered Ecoregions. Cemex, Mexico.

Morse-Jones, S., Bateman, I.J., Kontoleon, A., Ferrini, S., Burgess, N. and Turner, R.K. 2010: Testing the Theoretical Consistency of Stated Preferences for Tropical 

of East Anglia.

3 Naidoo, R., and T. Ricketts. 2006: Mapping economic costs and benefits of conservation. Plos Biology 4,2153-2164.

5 National Sample Census of Agriculture 2002-2003. (National Bureau of Statistics, Ministry of Agriculture and Food Security, Ministry of Water and Livestock Development, Ministry of Cooperatives and Marketing, Presidents Office, Regional Administration and Local Government, Ministry of Finance and Economic Affairs, 2007).

10 Osvaldo, E. S., Chapin III, F. S., Armesto, J. J., Berlow, E., Bloomfield, J., Dirzo, R., Huber-Sanwald, E., Huenneke, L. F., Jackson, R. B., Kinzig, A., Leemans, R., Lodge, D. M., Mooney, H. A., Oesterheld, M., Poff, N. L., Sykes, M. T., Walker, B. H., Walker, M., Wall, D. H., 2000: Global Biodiversity Scenarios for the Year 2100. Science 287, 1770-1774.

15 Peterson, G. D., Cumming, G. S., Carpenter, S. R., 2003: Scenario planning: a tool for conservation in an uncertain world. Conservation Biology 17(2), 358-366.

17 Raskin, P. D., 2005: Global scenarios: background review for the Millennium Ecosystems Assessment. Ecosystems 8(2), 133-142.

19 Rouget, M., R. M. Cowling, et al. 2006: Designing large-scale conservation corridors for pattern and process. Conservation Biology 20(2), 549-561.

21 Sheya, M. S., and S. J. S. Mushi. 2000: The state of renewable energy harnessing in Tanzania. Applied Energy 65,257-271. 
1 Strassburg, B., Turner, R. K., Fisher, B., Schaeffer, R. and Lovett, A. 2009: Reducing emissions from deforestation- the "combined incentives" mechanism and empirical simulations. Global Environmental Change 19:265-278.

4 Swetnam, R. D., Fisher, B., Mbilinyi, B. P., Munishi, P. K. T., Willcock, S., Ricketts, T., Mwakalila, S., Balmford, A., Burgess, N. D., Marshall, A. R., Lewis, S. L. (in press) Mapping socio-economic scenarios of land cover change: A GIS method to enable ecosystem service modelling. Journal of Environmental Management, doi:10.1016/j.jenvman.2010.09.007.

9 Tol, R. S. J. 2005: The marginal damage costs of carbon dioxide emissions: an assessment of the uncertainties. Energy Policy 33,2064-2074.

11 Turner, R. K. 2005: Integrated Environmental Assessment and Coastal Futures. In Vermaat, J., Brouwer, L., Turner,R.K. and Salomons, W. editors. Managing European Coasts: past, present and future. Springer, Berlin.

14 United Nations. 2005: Millennium Development Indicators Database. http:millenniumindicators.un.org/unsd/mi/mi_goals.asp

16 United Nations 2008: World Population Prospects: The 2008 Revision. Population

17 Division of Economic and Social Affairs of the United Nations Secretariat. 18 http://esa.un.org/unpp/.

19 Van Beukering P. et al., (2007) Optimization of the charcoal chain in Tanzania, Institute 20 for Environmental Studies, Vrije University.

21 Verburg, P. H., Schulp, C. J. E., Witte, N., Veldkamp, A., 2006: Downscaling of land use 22 change scenarios. Agriculture, Ecosystems and Environment 114, 39-56. 
1 Walz, A., Lardelli, C., Behrendt, H., Grêt-Regamey, A., Lundstrőm, Kytzia, S., Bebi, P., 2 2007: Participatory scenario analysis for integrated regional modelling. Landscape and Urban Planning 81, 114-131.

4 Xiang, W., Clarke, K. C., 2003: The use of scenarios in land-use planning. Environment 5 and Planning B: Planning and Design 30, 885-909.

6

7 
2 Table 1: Results of scoping studies on available data to map and value key ecosystem 3 series in the Eastern Arc Mountains of Tanzania.

\begin{tabular}{|c|c|c|}
\hline Category & Services and Benefits & Current Data \\
\hline Carbon & $\begin{array}{l}\text { Carbon storage, Carbon sequestration, Climate } \\
\text { regulation }\end{array}$ & $\begin{array}{l}\text { Forest plots }(\mathrm{n}=2,300), \\
\text { inventory for } 6 \text { forest blocks } \\
580 \mathrm{~km} \text { of forest disturbance } \\
\text { transects }\end{array}$ \\
\hline Timber / & Timber, Building materials (poles, thatch), & As above for carbon with \\
\hline $\begin{array}{l}\text { Non Timber Forest } \\
\text { Products }\end{array}$ & Bushmeat, Medicinal plants, Roots, Honey & $\begin{array}{l}\text { additional information from } \\
\text { household surveys in }>120 \\
\text { villages }\end{array}$ \\
\hline Water & $\begin{array}{l}\text { Water flow for households, irrigation and } \\
\text { hydropower, Flow regulation }\end{array}$ & $\begin{array}{l}\text { Rainfall monthly means, river } \\
\text { gauge data }\end{array}$ \\
\hline Pollination & $\begin{array}{l}\text { Forest species pollination, Agricultural } \\
\text { pollination }\end{array}$ & $\begin{array}{l}\text { Crop presence for mountain } \\
\text { blocks, pollinator species } \\
\text { presence }\end{array}$ \\
\hline Biodiversity & Genetic storage, Existence values & $\begin{array}{l}\text { Vertebrate and vascular plant } \\
\text { species lists for all mountain } \\
\text { blocks and most forest reserves, } \\
\text { regional inventories of birds, } \\
\text { reptiles, amphibians and } \\
\text { mammals }\end{array}$ \\
\hline All & & $\begin{array}{l}\text { Land cover, administrative and } \\
\text { census data, infrastructure (roads, } \\
\text { railways), soils, geology, climate } \\
\text { data }\end{array}$ \\
\hline
\end{tabular}

$41=$ Compendium from the last $10-15$ years

52 = from Sokoine University, Morogoro, Tanzania.

6 
2 Table 2: A comparison of the key socio-economic drivers embedded in the two scenarios 3 used in the land cover modelling: Matazamio Mazuri ('hopeful expectations') and Kama 4 Kawaida ("business-as- usual")

\begin{tabular}{|c|c|c|}
\hline Descriptor & Matazamio Mazuri (2025) & Kama Kawaida (2025) \\
\hline GDP growth & $6 \%$ & $5 \%$ \\
\hline GDP per capita & $\$ 1500$ & $\$ 1100$ \\
\hline Growth sectors & Tourism, Mining and Agriculture & Agriculture (area not productivity) \\
\hline Population growth & $2 \%$ & $3 \%$ \\
\hline Population by 2025 & 55 million & 60 million \\
\hline $\begin{array}{l}\text { Population with access } \\
\text { to electricity }\end{array}$ & $40 \%$ & $20 \%$ \\
\hline Energy sources & $\begin{array}{l}\text { Gas, coal, Hydro-electric Power } \\
\text { Biomass (firewood and charcoal) main } \\
\text { source for cooking but demand falling } \\
\text { through technology interventions } \\
\text { (stoves / waste residue fuels) }\end{array}$ & $\begin{array}{l}\text { Gas, some coal and HEP. } \\
\text { Biomass remains the main energy } \\
\text { source. }\end{array}$ \\
\hline Agricultural sector & $\begin{array}{l}\text { Remains largest employer and largest } \\
\text { component of GDP. } \\
\text { Marketing, processing and improved } \\
\text { transportation increases productivity. } \\
\text { Some expansion of irrigated } \\
\text { agriculture. } \\
\text { Livestock production increases. }\end{array}$ & $\begin{array}{l}\text { Remains largest employer and largest } \\
\text { component of GDP. } \\
\text { Productivity remains low with irrigated } \\
\text { agriculture rare. } \\
\text { Small-scale farming dominates with } \\
\text { much work still done by hand and hoe. }\end{array}$ \\
\hline
\end{tabular}

$\%$ area under medium-

Doubles to $30 \%$

Remains at $15 \%$

large-scale farming

Global financing

International payments for Carbon (through REDD) and PES schemes grow.

Payment schemes fail to be implemented in any significant manner.

Protected Areas

Increasingly well monitored and managed. Encroachment and illegal timber harvesting is arrested.

Integrated catchment management is improving.

Little capacity for monitoring and management.

Encroachment and illegal timber harvesting continues in reserves. Small-scale mining increases in the mountains. 
3 Table 3: Costs and Benefits of conversion of forest to agriculture in the Shagayu and

$4 \quad$ Image Forest Reserves.

\begin{tabular}{|c|c|c|c|c|c|c|}
\hline $\begin{array}{l}\text { Forest } \\
\text { Reserve }\end{array}$ & $\begin{array}{l}\text { Estimate } \\
\text { of stored } \\
\text { carbon } \\
\text { (mil. }\end{array}$ & $\begin{array}{l}\text { Carbon lost if } \\
\text { forest is } \\
\text { replaced by } \\
\text { agriculture }\end{array}$ & $\begin{array}{l}\text { Opportunity cost of } \\
\text { conservation } \\
\text { (charcoal and } \\
\text { agriculture) }\end{array}$ & $\begin{array}{l}\text { Management and } \\
\text { implementation costs } \\
\text { of conservation }\end{array}$ & $\begin{array}{l}\text { Necessary } \\
\text { carbon price to } \\
\text { offset costs* }\end{array}$ & $\begin{array}{l}\text { Number of } \\
\text { people } \\
\text { living } \\
\text { within } 5 \mathrm{~km}\end{array}$ \\
\hline
\end{tabular}
tonnes) (mil. tonnes

\begin{tabular}{|c|c|c|c|c|c|c|}
\hline & & $\mathrm{CO}_{2 \mathrm{e}}$ & & & & \\
\hline Shagayu & 2.6 & 5.1 & $\$ 10.3$ million & $\$ 233$ thous. & $\$ 2.06 / \mathrm{tCO}_{2}$ & 35793 \\
\hline Image & 2.5 & 3.3 & $\$ 5.67$ million & $\$ 162$ thous. & $\$ 1.70 / \mathrm{tCO}_{2}$ & 637 \\
\hline
\end{tabular}

5

$6 *$ Reported in $\$ / \mathrm{tCO}_{2}$ where $1 \mathrm{tCO}_{2}=1 / 3.667 \mathrm{tC}$ 
2 List of Figures

3 Figure 1. Eastern Tanzania showing the Eastern Arc Mountain chain. While the focal

4 ecosystem service production areas are outlined in black, the beneficiaries stem from

5 local to global.

6

7 Figure 2. Series of sequential mapping exercises for assessing ecosystem services across

8 a landscape.

10 Figure 3. Possible spatial relationships between service production units $(\mathrm{P})$ and service

11 benefit units (B). In panel 1, both the service provision and benefit occur at the same

12 location (e.g. soil formation, provision of raw materials). In panel 2 the service is

13 provided omni-directionally and benefits the surrounding landscape. This delivery can

14 happen at local scales such as for pollination or pest control (dashed line) upto the global

15 scale such as in carbon sequestration (solid line). Panel 3 demonstrates services that have

16 specific directional benefits. For example, uphill forested areas provide water regulation

17 services to both local (dashed line) and regional (solid line) (based on Fisher et al., 2009)

19 Figure 4. Changes in carbon storage for the Shagayu and Image reserves when moving

20 from montane forests to agricultural land (left). Forest reserve boundaries and village

21 locations within a $5 \mathrm{~km}$ buffer (right)

22

23

24 